\title{
Morphological variation and life history changes of a Daphnia hyalina population exposed to Chaoborus flavicans larvae predation (L. Candia, Northern Italy)
}

\author{
Nicoletta RICCARDI*, Gianluigi GIUSSANI and Laurence LAGORIO ${ }^{1)}$ \\ CNR Istituto per lo Studio degli Ecosistemi, Largo Tonolli 50, 28922 Verbania Pallanza, Italy \\ ${ }^{1)}$ Institut Universitaire de Technologie, Departement Genie Biologique, Université de Toulon et du Var, BP 132, 83957 La Garde \\ Cedex, France \\ *e-mail corresponding author: n.riccardi@iii.to.cnr.it
}

\begin{abstract}
The response of Daphnia populations to invertebrate predators involves morphological changes and can lead to a trade-off between growth-and reproduction-related traits. The effects of Chaoborus flavicans larvae on the Daphnia hyalina population in Lake Candia were investigated by comparing the morphometric characteristics and life history traits of the preys during one year with low predator density and one year with a ten fold higher predator density. The increase in Chaoborus density seems to have induced morphological changes in Daphnia hyalina which enabled the modified morph to coexist with the predator. The predator impact did not result in any apparent shift in body size pattern of the prey population, while an increase in average clutch size and a tendency towards a decrease in size at first reproduction suggests the possibility of a predator-mediated shift in life history traits.
\end{abstract}

Key words: Daphnia, predation, Chaoborus, Lake Candia, body size, clutch size

\section{INTRODUCTION}

Invertebrate predators, such as Chaoborus larvae, play a major role in structuring zooplankton communities in lakes both in directly limiting prey populations (e.g. Dodson 1972; Fedorenko 1975; Neill 1984; Hanazato 1990) and in altering, through size selective removal of individuals, the size and age structure as well as the dynamics of prey populations (e.g. Neill 1981; Mumm 1997). Prey populations can react to predator pressure by developing morphological or behavioural defenses, as well as by adjusting their lifehistory strategies to become less susceptible to the predator. Morphological responses of some Daphnia species to Chaoborus chemical cues include the production of neck spines, enlarged helmet crests or elongated tail spines (e.g. Krueger \& Dodson 1981; Havel 1987; Repka et al. 1995), which seem to reduce prey vulnerability by lowering predator's perception and strike efficiency and/or by increasing prey's escape ability (e.g. Mort 1986; Swift 1992). Variations in life-history strategies to maximise fitness in the presence of predators can result from a change in energy allocation patterns for growth and reproduction to compensate the cost for producing morphological defenses. A reduction of fecundity, mainly due to delayed juvenile development and thus a later age at maturity, is frequently observed in Daphnia exposed to Chaoborus predation (e.g. Black \& Dodson 1990; Riessen \& Sprules 1990; Stibor \& Lüning 1994).
During the last fifteen years the zooplankton of Lake Candia experienced several environmental changes resulting from biomanipulation and aquatic plants management (Giussani et al. 1990; Galanti et al. 1990; Giussani \& Galanti, 1995). In the frame of the long term limnological survey of this lake, zooplankton populations have been studied since 1986 (Giussani et al., unpublished data). The density of Chaoborus larvae in Lake Candia increased since 1997 attaining in summer 1998 values about a ten fold higher than those observed in previous years (1986-1996) when their density in summer averaged 0.15 ind $1^{-1}$. From June to September 1998 the abundance of larvae in the water column ranged from 0.6 to 2.6 ind $1^{-1}$. A strong decrease of Daphnia hyalina population was concurrently observed which suggested an increase of mortality by predation. This study aimed to assess whether the increased predation pressure has induced morphological and/or physiological reactions in the prey population as well as some changes in its size structure. To this end we analyzed the size structure, morphology and life history traits of Daphnia hyalina during one year with a low Chaoborus density (1996) and one year with a high Chaoborus density (1998).

\subsection{Study site}

Lake Candia is a small $\left(1.49 \mathrm{~km}^{2}\right)$, shallow (maximum depth $=7.7 \mathrm{~m}$; mean depth $=3.8 \mathrm{~m}$ ) eutrophic water body located in the subalpine area near Torino (Piedmont, Northern Italy). It has a relatively small 
drainage area $\left(9.9 \mathrm{~km}^{2}\right)$ mainly devoted to agriculture and its most important water sources are represented by internal springs, precipitation and runoff. Following the manifestation of eutrophication effects, such as mass mortality of fish and massive blue-green algae blooms, which reduced lake fruition for recreational aims, the lake was made object of studies to elaborate a plan for its recovery. The diversion of the municipal sewage of the small town of Candia was not sufficient to improve significatively lake conditions within a reasonable time mainly because of the high internal nutrient load. Biomanipulation was, therefore, considered as an alternative to other direct interventions on the water body to accelerate its recovery. In 1986 and 1987 most of the rudd (Scardinius erythrophthalmus) biomass was removed to reduce fish predation on zooplankton, thus favouring the increase of zooplankton control on phytoplankton. A detailed description of the biomanipulation practices applied to the lake is reported in Giussani et al. (1990) and Giussani \& Galanti (1995). In addition, the annual harvesting of floating macrophytes (water chestnut) to reduce internal nutrient supply and to enhance the accessibility of the littoral area for ichthyophagous fish spawning has been employed since 1986 (Galanti et al. 1990).

\section{MATERIAL AND METHODS}

Since 1986 zooplankton samples have been collected monthly or forthnightly from March to December by vertical tows from the bottom to the surface with an open net of $126 \mu \mathrm{m}$ mesh. Each sample was obtained by pooling nine replicate hauls (corresponding to 1475 liters of filtered water) collected in three stations located along the major axis of the lake according to the direction of the prevailing winds. The animals were filtered on a $50 \mu \mathrm{m}$ nylon net and killed by immersion in $95 \%$ ethanol before preservation in a $5 \%$ neutralized $\left(\mathrm{CaCO}_{3}\right)$ formaldehyde solution. The use of alcohol prevents carapace ballooning and the loss of eggs/embryos from the brood pouch.

Water samples for total chlorophyll and phytoplankton analysis have been collected on the same dates of zooplankton sampling. A detailed description of the methods is reported in previous publications (Giussani et al. 1990; Giussani \& Galanti 1995; Morabito \& Oggioni 2001).

For the aim of the present study the zooplankton samples collected between March and October 1996 (8 samples) and 1998 (11 samples) were reanalyzed as follows.

The number of Chaoborus larvae and the relative abundance of each development stage were estimated by microscopical analysis of the whole sample. The head capsule length of 50 larvae for each instar was measured by an eyepiece micrometer (100 subdivisions) at a magnification of $40 \times$ and the mouth width esti- mated as approximately a half of the head capsule length (Mumm \& Sell 1995).

The abundance of Daphnia, the number of females carrying eggs and the number of eggs or embryos in the brood pouch of these latter were estimated on subsamples corresponding to at least $25 \%$ of the total sample volume. Measurements of total length (TL, from the anterior end of the carapace to the base of the tailspine), helmet length (HL, from the anterior end of the carapace to the ideal line drawn from the upper side of the eye perpendicularly to the major body axis) and tailspine length (TSL) were performed on 100 Daphnia per sample by a PC, connected to the microscope, provided with an image analysis software. Body length (BL) was calculated by difference between total length and helmet length. Since the most important measure affecting the susceptibility of the prey is the maximum width of the body (Swift 1992) the carapace width of 50 daphnids per sample was also measured.

The smallest adult size class (primipara) was determined as the size class in which at least $5 \%$ of the total number of egg bearing females was observed. The minimum amount of $5 \%$ ensured that the smallest adult size class would not be set by a single precociously reproducing female (Caramujo et al. 1997). The proportion of juveniles (JUV), adults with eggs $(\mathrm{AD}+)$ and adults without eggs (AD-) in each $0.1 \mathrm{~mm}$ size class was estimated from size measurements.

Fecundity (F) was calculated as the average number of eggs per adult female. Egg development time, needed to estimate birth rate, was calculated according to Bottrell et al. (1976) using the water temperature (weighted mean on the water column) at each sampling date. Birth rate was calculated by Paloheimo's (1974) equation.

Two-way ANOVA was applied to the average clutch size, size at first reproduction, body length, helmet length and tailspine length of Daphnia with year and month as factors. To identify the differences due to the different Chaoborus density in the two years only the summer and autumn data have been included in the analysis. In this case years have been assumed to represent two different treatments.

The Kolmogorov-Smirnov two-sample test (Sokal \& Rohlf 1995) was used to test the differences between the population size distribution in 1996 and 1998. To identify the differences due to the predator impact and to minimize the seasonal effect the test was applied to the June-October pooled data of each year.

Spearman's coefficient of rank correlation was calculated to measure the intensity of association observed between Chaoborus density and helmet length/body length and tailspine length/body length ratio of Daphnia juveniles and adults. The degree of association between average clutch size and chlorophyll concentration was also measured by Spearman's correlation. 


\section{RESULTS}

The weighted mean of temperature over the water column ranged from 5.2 to $25.8^{\circ} \mathrm{C}$ in 1996 and from 9.0 to $25.8^{\circ} \mathrm{C}$ in 1998 , showing a similar pattern of variation over the two years.

Conversely, chlorophyll concentration was generally higher in 1998 than in 1996 with mean annual values of 21 and $11 \mu \mathrm{g} \mathrm{l}^{-1}$ respectively. This difference reflected both quali- and quantitative differences in the phytoplankton association, mainly due to the development of large colonial algae during 1998 (Morabito \& Oggioni 2001). The total phytoplankton abundance and biomass were higher in 1998 than in 1996: phytoplankton density ranged from about 660 to 255.000 cell ml$^{-1}$ with a mean biomass of $4100 \mathrm{~mm}^{3} \mathrm{~m}^{-3}$ in 1998 and from 550 to 191.000 cell ml${ }^{-1}$ with a mean biomass of $1870 \mathrm{~mm}^{3} \mathrm{~m}^{-3}$ in 1996 (Morabito \& Oggioni 2001).

The density of Daphnia was similar in the two years in March-April and from July to October (Fig. 1). In 1996 the decrease observed in March-April was followed by an increase in May-June, while in 1998 the population density continuously declined from March to September when it was reduced to less than 0.5 ind $1^{-1}$. In 1996 the Daphnia population was mostly composed by juveniles except in March and April. Conversely, in 1998 juveniles were relatively more abundant than adults only in March-April and in October.
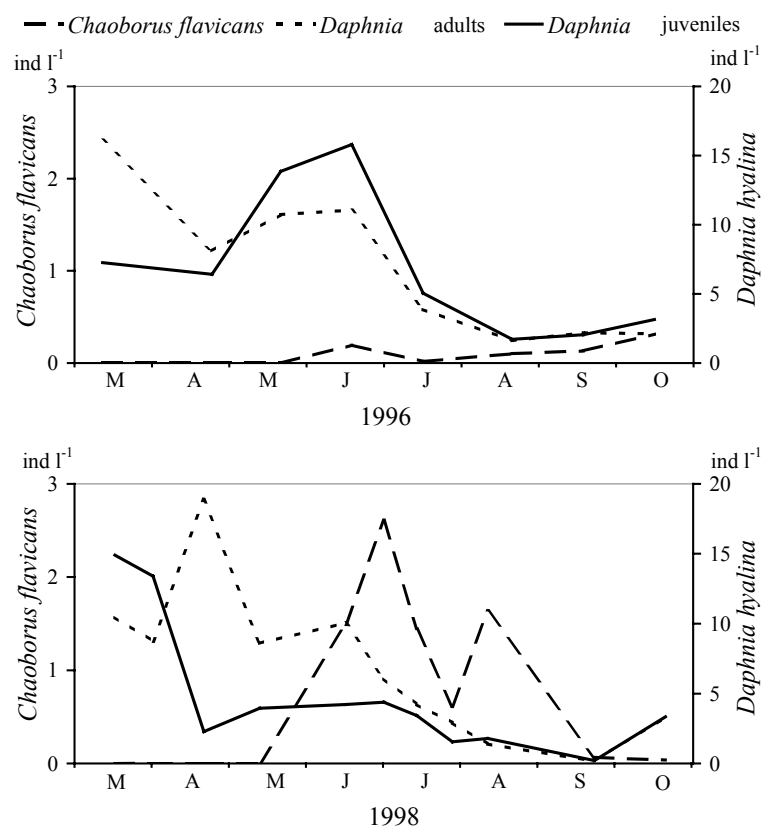

Fig. 1. Seasonal variation in the density of Chaoborus flavicans and Daphnia hyalina (adults and juveniles) from March to October 1996 and 1998.

In both the years the larvae of Chaoborus first appeared in the water column in June and were still present in October. In summer 1998 their density sharply in- creased to attain a value about ten fold higher than in 1996 (Fig. 1). From June to September 1998 the abundance of larvae in the water column ranged from 0.6 to 2.6 ind $\mathrm{l}^{-1}$. The relative abundance of the later instars (III and IV) increased from June to August while decreased in September probably due to emergence of the adults (Fig. 2). The average mouth width varied from about $100 \mu \mathrm{m}$ in the $1 \mathrm{st}$ instar larvae to $550 \mu \mathrm{m}$ in the 4th instar larvae (Tab. 1).

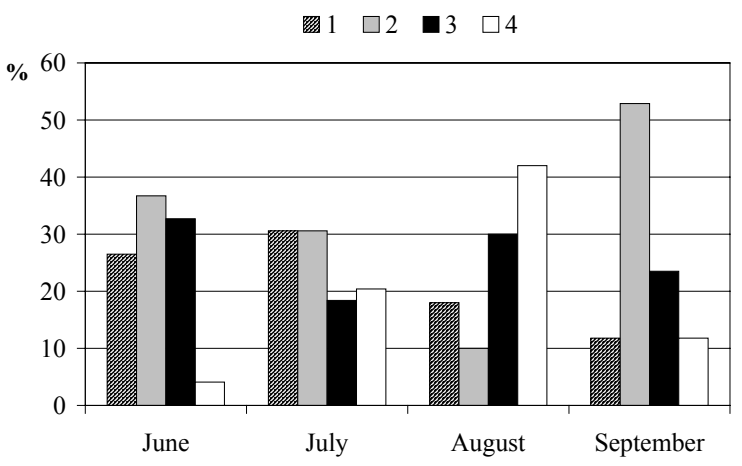

Fig. 2. Changes in the percentage of the different instars $(1,2$, 3, 4) of Chaoborus flavicans from June to September 1998.

Tab. 1. Mean and range of variation of mouth width of Chaoborus flavicans.

\begin{tabular}{ccc}
\hline Instar & \multicolumn{2}{c}{ Mouth width $(\mu \mathrm{m})$} \\
\cline { 2 - 3 } & Mean & Range \\
\hline 1 & 105 & $99-109$ \\
2 & 201 & $188-248$ \\
3 & 352 & $322-416$ \\
4 & 551 & $519-618$ \\
\hline
\end{tabular}

The carapace width of daphnids ranged from about 170 to $900 \mu \mathrm{m}$ increasing with total length according to the equation: width $=0.51$ length $-77.41\left(\mathrm{R}^{2}=0.88\right)$. It can therefore be estimated that the individuals with a total body length lower than about $1100 \mu \mathrm{m}$ were susceptible to Chaoborus predation. Daphnia length ranged from 440 to $1830 \mu \mathrm{m}$, but during summer months (JuneOctober) about $70 \%$ of the population was represented by individuals smaller than $1100 \mu \mathrm{m}$.

No evidence of any possible effect of size selective predation was found by comparing the Daphnia population size structure in the summer periods (June - October) of 1996 and 1998 (Fig. 3), as testified by the not significative Kolmogorov-Smirnov test (Tab. 2).

Most of the Daphnia collected in 1998 during the period of Chaoborus presence in the water column showed a higher helmet than those collected in 1996. Based on the body shape, two distinct morphotypes of Daphnia hyalina can be distinguished: a "normal" morphotype with a round shaped head and a toothed morphotype with a spined helmet. In 1996 helmet length was similar in the two morphotypes. 

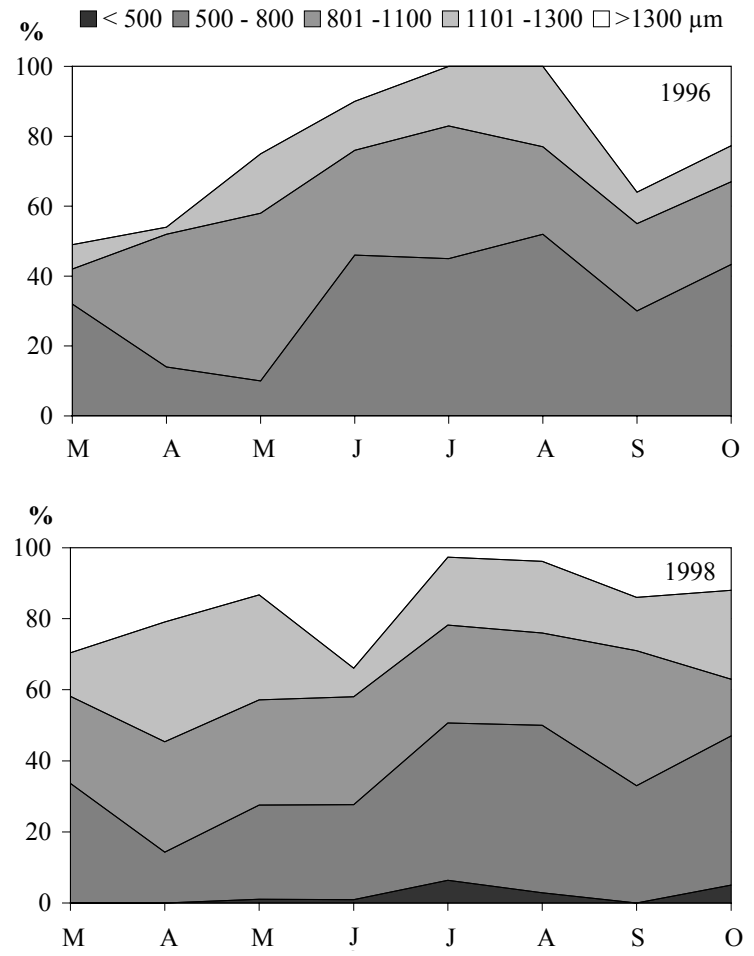

Fig. 3. Daphnia population size structure in 1996 and 1998.

Tab. 2. Percent difference in the relative frequency of individuals in the five size classes in 1996 compared to 1998. The Kolmogorov-Smirnov two-sample test results as follows: $\mathrm{D}_{0.05}=0.079$ (n.s.).

\begin{tabular}{cc}
\hline$\mu \mathrm{m}$ & June-October \\
\hline$<500$ & 3.9 \\
$500-800$ & -3.2 \\
$800-1100$ & -1.6 \\
$1100-1300$ & 8.7 \\
$>1300$ & -9.5
\end{tabular}

Conversely, in 1998 a sharp increase in helmet length occurred since June in the toothed morphotype and the difference between the two morphotypes became more and more evident from July to October, resulting in a correspondent increase in the ratio of helmet length to body length (HL/BL) (Fig. 4). The toothed morphotype was characterized by a longer tailspine length than the normal morphotype resulting in a higher tailspine length to body length ratio (TSL/BL) (Fig. 4). Both the morphotypes showed a tendency towards an increase in tailspine length in June-October 1998. The difference in the HL/BL and TSL/BL ratios between 1996 and 1998 summer and autumn months was remarkable in juveniles, smaller but still evident in adults. Body length was generally shorter in the toothed morphotype and decreased in summer in both the morphotypes (Fig. 5). This decrease was more evident in 1998 than in 1996 both for juveniles and adults. The contemporary increase of helmet length in the same period of
1998 compensated for the decrease in body length resulting in a total length similar between the two years (Tab. 3). The incidence of the toothed morphotype on the total population increased from spring to autumn in both years but was particularly remarkable in 1998 (Fig. 6). Indeed, after June more than $50 \%$ of the population was represented by toothed individuals and the proportion was always higher than $70 \%$ for juveniles. In particular, in 1998 the smaller size classes $(<550 \mu \mathrm{m}$ width, corresponding to $<1100 \mu \mathrm{m}$ length) were almost completely composed by toothed individuals between June and October.

A significative difference between the morphometric characteristics (BL, HL and TSL) of the population in the two years (Tab. 3) resulted from the increased proportion of toothed individuals in 1998. Both HL/BL and TSL/BL ratios were positively correlated with Chaoborus density $(\mathrm{r}=0.762, \mathrm{df}=19 ; \mathrm{p}=0.0002 ;$ and $\mathrm{r}=$ $0.664, \mathrm{df}=19 ; \mathrm{p}=0.0019$ ).

The percentage of adult females was higher in 1998 than in 1996 (Tab. 4) while no clear difference between the two years was observed in the proportion of egg carrying females. However, in 1998 the average clutch size was significantly higher than in 1996 (Tabs 3 and 4) resulting in proportionally higher fecundity and birth rate (Tab. 4). Average clutch size was positively correlated with chlorophyll concentration $(\mathrm{r}=0.588, \mathrm{df}=19 ; \mathrm{p}=$ $0.0081)$. A significant reduction in size at first reproduction was also observed in 1998 (Tabs 3 and 4).

\section{DISCUSSION AND CONCLUSIONS}

The density of Chaoborus larvae in Lake Candia increased since 1997 attaining in summer 1998 values about a ten fold higher than in previous years (19861996; unpublished data). The abundance of larvae in 1998 can be considered low to intermediate when compared to literature data (e.g. Goldspink \& Scott 1971; Hillbricht-Ilkowska et al. 1975; Iwakuma et al. 1989; Mumm 1997). However, several studies have shown that even at moderate density Chaoborus can have a significant impact on zooplankton populations (e.g. Dodson 1972; Luecke \& Litt 1987; Vanni 1988; Hanazato \& Yasuno 1989) and a theoretical model developed by Riessen (1992) predicts that Chaoborus densities $>0.5$ ind $\mathrm{l}^{-1}$ are sufficient to cause a reduction in Daphnia population density. Therefore, the stronger decrease in Daphnia abundance during summer 1998, if compared to 1996 , is likely due to an increased mortality by predation. This hypothesis seems to be matched by the lower proportion of juveniles in the $1998 \mathrm{popu}-$ lation: in particular the maximum peak of egg production observed in May (about 20 eggs ${ }^{-1}$ ) seems not to have resulted in a corresponding increase in the number of juveniles. Since the successive sampling occurred about a month later, that is a long time compared to the egg development time at the mean temperature of that period (3-5 days), the newborn cohort may have been 


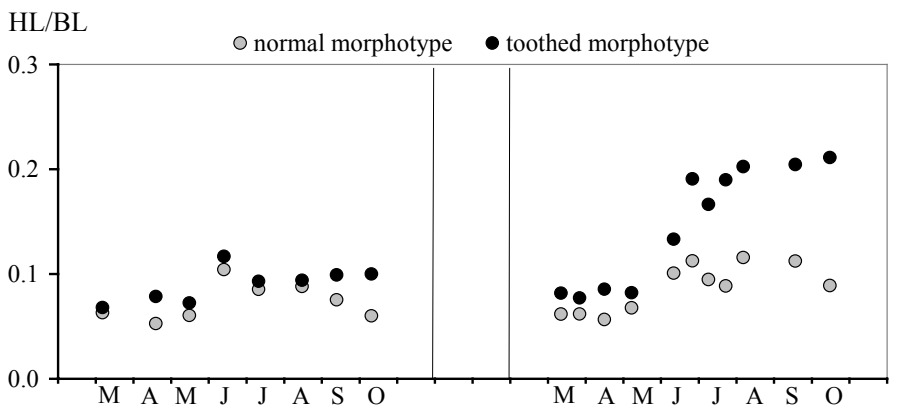

$\mathrm{TSL} / \mathrm{BL}$

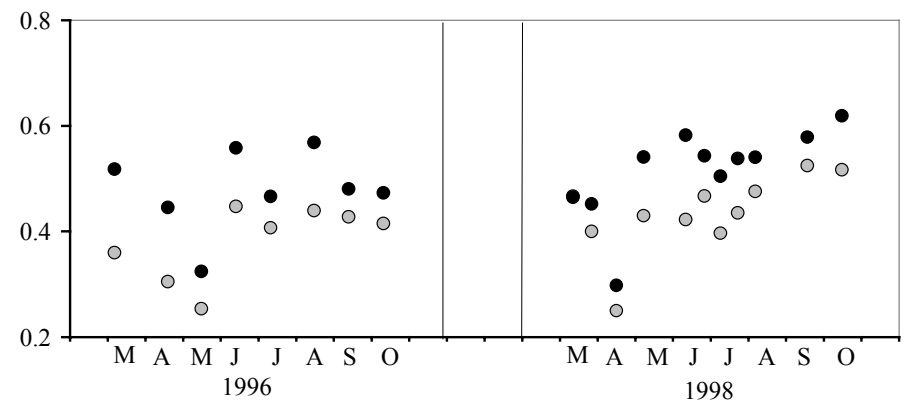

Fig. 4. Changes in the helmet length/body length ratio and in the tailspine length/body length ratio of the normal and toothed morphotypes during 1996 and 1998.
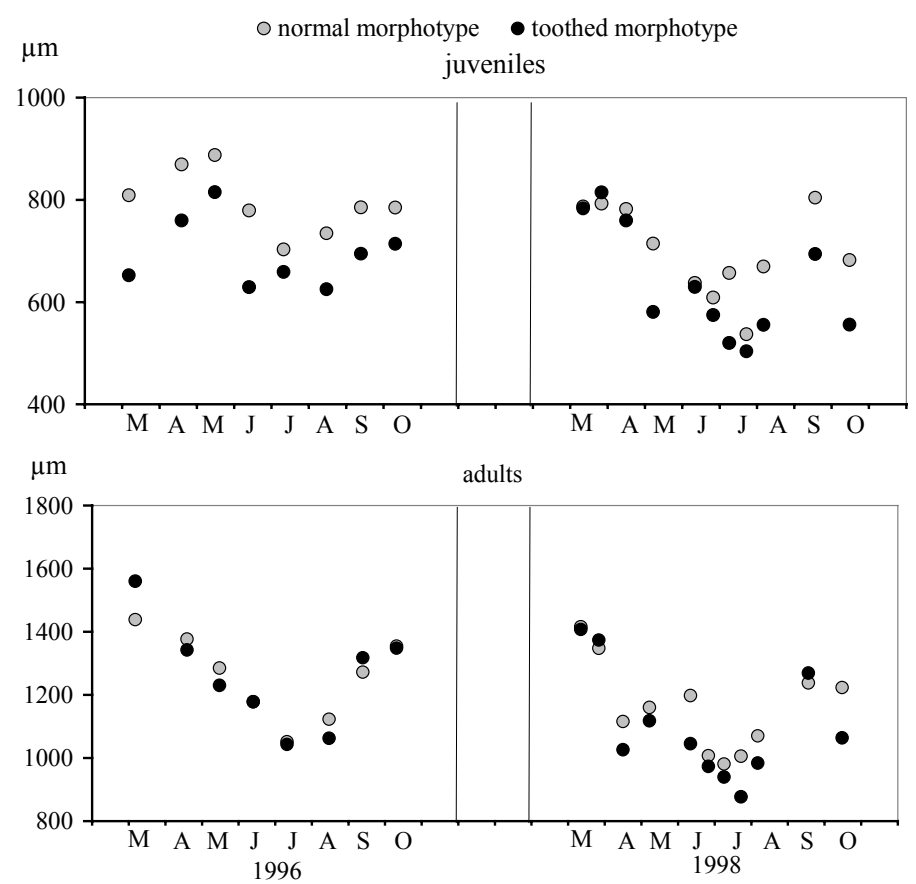

Fig. 5. Changes in the body length of normal and toothed morphotypes (both juveniles and adults) during 1996 and 1998.

missed. However, an increase of total population density should have been observed, even after one month, in absence of a high mortality rate.

The high predation pressure in 1998 resulted in the development of morphological changes in the Daphnia hyalina population which seem to be anti-predator devices, as have been described in various Daphnia spe- cies exposed to Chaoborus cues (e.g. Krueger \& Dodson 1981; Hebert \& Greve 1985; Hanazato \& Yasuno 1989).

Since Chaoborus is an ambush predator, its selective impact on different prey items is mainly related to differential prey vulnerability which is an optimum function resulting from the encounter probability between 
Tab. 3. Results of the two-way ANOVA with year and months (from June to October) as factors. Traits: average clutch size (CLS), size at first reproduction (SFR), body length (BL), helmet length (HL), tailspine length (TSL) and total length (TL). *: p <0.05, **: p $<0.01, * * *: \mathrm{p}<0.001$.

\begin{tabular}{|c|c|c|c|c|c|c|c|c|c|c|c|c|c|}
\hline & \multirow[b]{2}{*}{ df } & \multicolumn{2}{|c|}{ CLS } & \multicolumn{2}{|c|}{ SFR } & \multicolumn{2}{|c|}{ BL } & \multicolumn{2}{|c|}{$\mathrm{HL}$} & \multicolumn{2}{|c|}{ TSL } & \multicolumn{2}{|r|}{$\mathrm{TL}$} \\
\hline & & MS & $F$ & MS & $F$ & MS & $F$ & MS & $F$ & MS & $F$ & MS & $F$ \\
\hline year & 1 & 70.29 & $46.83^{* * *}$ & 28390 & $7.679^{* *}$ & 664200 & $9.829^{* *}$ & 649800 & $340.800^{* * *}$ & 293100 & $48.690^{* * *}$ & 78.20 & 0.00098 n.s. \\
\hline month & 4 & 10.51 & $7.003^{* * *}$ & 1203000 & $32.530^{* * *}$ & 1060000 & $15.690^{* * *}$ & 11780 & $6.180^{* * *}$ & 298600 & $49.610^{* * *}$ & 1239000 & $15.67^{* * *}$ \\
\hline interaction & 4 & 7.190 & 4.791 & 14380 & 3.888 & 738100 & 10.92 & 14370 & 7.537 & 32460 & 5.393 & 563700 & 7.127 \\
\hline
\end{tabular}

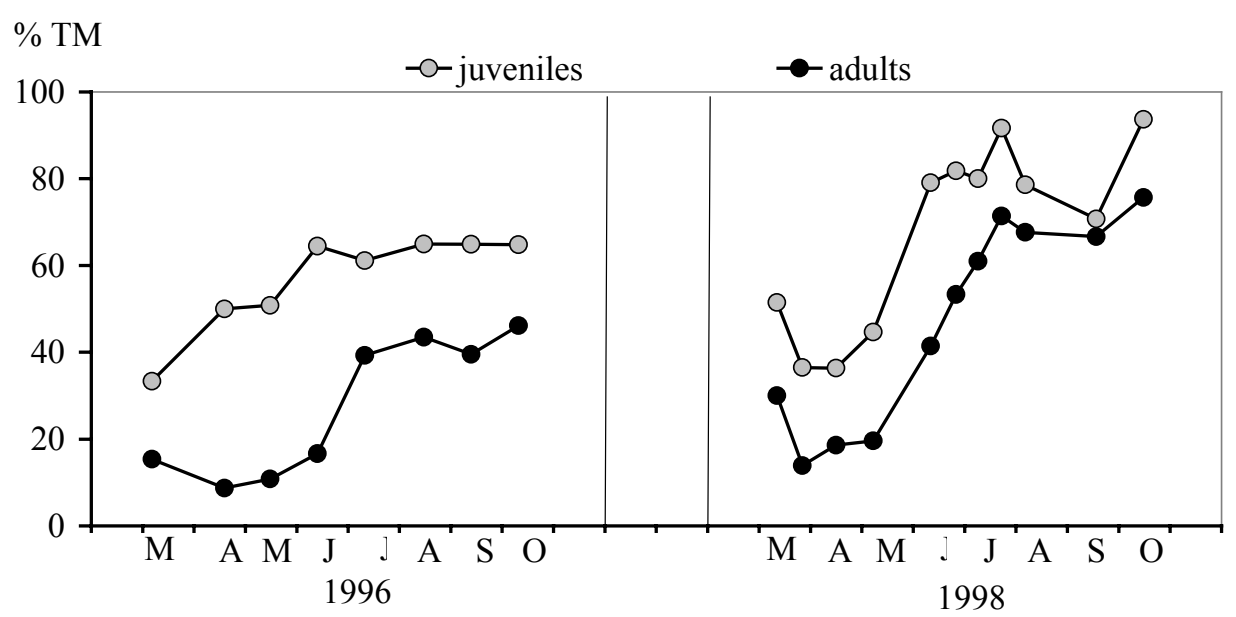

Fig. 6. Variation in the percentage of toothed morphotype on the total number of Daphnia juveniles and adults in 1996 and 1998.

Tab. 4. Mean values and range (in brackets) of the percentage of adult and egg carrying females on the total number of individuals, average clutch size, fecundity (egg ratio), birth rate and primipara mean size in 1996 and 1998.

\begin{tabular}{lcc}
\hline & 1996 & 1998 \\
\hline \% adult females & $35.0(23.0-46.0)$ & $44.2(18.0-88.7)$ \\
\% egg carrying females & $21.9(10.6-35.3)$ & $22.5(5.0-34.3)$ \\
Average clutch size & $2.00(1.13-2.61)$ & $3.09(1.08-4.25)$ \\
Fecundity $\left(\right.$ eggs adult female $\left.^{-1}\right)$ & $1.49(0.46-1.88)$ & $2.18(0.25-3.67)$ \\
Birth rate $\left(\right.$ days $\left.^{-1}\right)$ & $0.13(0.04-0.23)$ & $0.19(0.03-0.28)$ \\
Size at first reproduction $(\mu \mathrm{m})$ & $1244(1052-1377)$ & $1155(986-1322)$ \\
\hline
\end{tabular}

predator and prey (increasing with prey size) and the strike efficiency (decreasing with prey size) (Pastorok 1981). As a result of the interaction of these two factors, medium sized preys are predicted to experience the highest predation mortality (Pastorok 1981; Riessen 1992). Morphological changes (e.g. Havel 1987) and life history shifts (e.g. Black \& Dodson 1990; Stibor 1992) developed by preys are expected to be favoured if they reduce prey vulnerability by providing a direct protection (e.g. interfere mechanically with handling or reduce predator perception of the prey) or an escape in size. Daphnia hyalina of Lake Candia developed a morph characterized by a longer helmet, provided with one or two spines, and a longer tailspine, while total body length did not increased because of a reduction of the distance between the eye and the base of the tailspine. Helmet and tailspine elongation probably provided a defense by changing the body shape. This may have caused an interference with predator's handling and/or perception and/or enabled prey to swim faster to better escape the predator (e.g. Mort 1986; Swift 1992). The progressive increase in the percentage of the toothed morph between June and October 1998 suggests a strong negative predator selection against the modified morphotype. A differential survival between the two morphotypes is also supported by the fact that the highest frequency of toothed individuals was found in the smaller size classes, falling within the preferred size range of Chaoborus.

An evolution towards larger body size is expected to occur in Daphnia populations exposed to Chaoborus predation (e.g. Havel \& Dodson 1987; Spitze 1991; Riessen 1994). In the case of D. hyalina in Lake Candia nor an increase in body size at maturity neither a change in the population size structure clearly related to size selective predation were observed. According to Ries- 
sen (1994) an increase in body size is advantageous only beyond a threshold body size pattern, above which increases in body size are highly advantageous in the presence of Chaoborus predation, but below which such increases in body size provide little or no advantage. Obviously, the threshold for gaining an advantage in increasing body size is related to both predator mouth width and prey size, both of which depend on the species. It seems possible that for the relatively "small" $D$. hyalina of Lake Candia there was no advantage in increasing body size because this would result in a relatively small percentage of adult individuals which could escape Chaoborus predation. Indeed, switching from positive to negative preference is expected to occur around $1.1 \mathrm{~mm}$ of prey length, a value below which fell more than $70 \%$ of the individuals during summer months. This threshold value fall in the range (0.96-1.24 $\mathrm{mm}$ ) measured by Krylov (1992) for fourth instar larvae of C. flavicans.

Several studies have shown that the development of antipredator morphological changes often impose a cost in terms of reduced fecundity (e.g. Havel \& Dodson 1987; Black \& Dodson 1990; Riessen \& Sprules 1990; Caramujo \& Boavida 2000). On the contrary, in D. hyalina of Lake Candia an increase in fecundity and birth rate occurred in 1998. The removal of juveniles by predation resulted in a higher proportion of adult individuals with a consequent increase of the egg ratio. Since birth rate linearly depends on egg ratio, a reduction in the relative proportion of juveniles leads to a corresponding increase in birth rate. A similar effect was observed in Daphnia longispina exposed to strong Chaoborus predation in enclosure experiments in Plußsee (Mumm 1997).

However, in 1998 we also observed an increase in average clutch size, which is independent from the relative proportion of juveniles and adults. This increase in average clutch size could be explained with increased food availability in 1998. Daphnids could have taken advantage of the better food conditions to compensate the cost for morphological defenses induction with an increased energy intake. The increased energy intake was not completely allocated to the development of defensive spines but also allowed an increased reproductive effort. In addition, a trend towards a reduction in the primipara size was observed, suggesting the hypothesis of a predator-induced shift in the energy allocation pattern. Invertebrate predation is generally expected to induce a delayed maturity and an increase in size at first reproduction while an opposite shift seems to be favoured under fish predation (e.g. Taylor \& Gabriel 1992; Lampert 1994; Riessen 1999). However, several factors influence growth patterns and life histories resulting in a wide variation of responses (Taylor \& Gabriel 1992; Spitze 1991).

In conclusion, Chaoborus density increase in Lake Candia induced morphological changes in D. hyalina which enabled the modified morph to coexist with the predator. The predator impact did not result in any apparent shift in body size pattern of the prey population while an increase in average clutch size and a tendency towards a decrease in size at first reproduction suggests the possibility of a predator-mediated shift in life history traits.

\section{AKNOWLEDGMENTS}

We are indebted to the colleagues Aldo Marchetto, Giuseppe Morabito and Oscar Ravera for their valuable suggestions and constructive comments on earlier versions of the manuscript. A special thank is due to Roberto Bertoni for technical assistance with image analysis software, to Igor Cerutti for his valuable help during samples collection, to Teresa Ruffoni for zooplankton counting and to Sandra Spence for the English revision. We also tank the reviewers, Ireneo Ferrari and Fiorenza Margaritora, for substantially improving the manuscript.

\section{REFERENCES}

Black, A.R. \& S.I. Dodson. 1990. Demographic costs of Chaoborus-induced phenotypic plasticity in Daphnia pulex. Oecologia (Berlin), 83: 117-122.

Bottrell, J., A. Duncan, Z.M. Gliwicz, E. Grygierek, A. Herzig, A. Hillbricht-Ilkowska, H. Kurasawa, P. Larsson \& T. Weglenska. 1976. A rewiev of some problems in zooplankton production studies. Norw. J. Zool., 24: 419456.

Caramujo, M.-J., M.C. Crispim \& M.-J. Boavida. 1997. Assessment of the importance of fish predation versus copepod predation on life history traits of Daphnia hyalina. Hydrobiologia, 360: 243-252.

Caramujo, M.-J. \& M.-J. Boavida. 2000. Induction and costs of tail spine elongation in Daphnia hyalina x galeata: reduction of susceptibility to copepod predation. Freshwater Biol., 45: 413-423.

Dodson, S.L. 1972. Mortality in a population of Daphnia rosea. Ecology, 53: 1011-1023.

Fedorenko, A.Y. 1975. Feeding characteristics and predation impact of Chaoborus (Diptera, Chaoboridae) larvae in a small lake. Limnol. Oceanogr., 20: 250-258.

Galanti, G., P. Guilizzoni \& V. Libera. 1990. Biomanipulation of Lago di Candia (Northern Italy): a three-year experience of aquatic macrophyte management. In: Gulati, R.D., E.H.R.R. Lammens, M.-L. Mejier \& E. van Donk (Eds), Biomanipulation - Tool for Water Management. Hydrobiologia, 200-201: 409-417.

Giussani, G., R. de Bernardi \& T. Ruffoni., 1990. Three years of experience in biomanipulating a small eutrophic lake: Lago di Candia (Northern Italy). In: Gulati, R.D., E.H.R.R. Lammens, M.-L. Mejier \& E. van Donk (Eds), Biomanipulation - Tool for Water Management. Hydrobiologia, 200-201: 357-366.

Giussani, G. \& G. Galanti. 1995. Case study: Lake Candia (Northern Italy). In: de Bernardi, R. \& G. Giussani (Eds), Biomanipulation in Lakes and Reservoirs Management. Vol. 7. Guidelines of Lake Management. ILEC, UNEP: 135-146.

Goldspink, C.R. \& D.B. Scott. 1971. Vertical migration of Chaoborus flavicans in a Scottish loch. Freshwat. Biol., 1: 411-421. 
Hanazato, T. 1990. A comparison between predation effects on zooplankton communities by Neomysis and Chaoborus. Hydrobiologia, 198: 33-40.

Hanazato, T. \& M. Yasuno. 1989. Zooplankton community structure driven by vertebrate and invertebrate predators. Oecologia, 81: 450-458.

Havel, J.E. 1987. Predator-induced defenses: a review. In: Kerfoot W.C. \& A. Sih (Eds), Predation: direct and indirect impacts on aquatic communities. University Press of New England, Hanover, N.H.: 263-278.

Havel, J.E. \& S.I. Dodson. 1987. Reproductive costs of Chaoborus-induced polymorphism in Daphnia pulex. Hydrobiologia, 150: 273-281.

Hebert, P.D.N. \& P.M. Grewe. 1985. Chaoborus-induced shifts in the morphology of Daphnia ambigua. Limnol. Oceanogr., 30: 1291-1297.

Hillbricht-Ilkowska, A., Z. Kajak, J. Ejsmont-Karabin, A. Karabin \& J. Rybak. 1975. Ecosystem of the Mikolajskie Lake. The utilization of the consumers production by invertebrate predators in pelagic and profundal zones. Pol. Arch. Hydrobiol., 22: 53-64.

Iwakuma, T., K. Shibata \& T. Hanazato. 1989. Production ecology of phyto- and zooplankton in a eutrophic pond dominated by Chaoborus flavicans (Diptera: Chaoboridae). Ecol. Res., 4: 31-53.

Krueger, D.A. \& S.I. Dodson. 1981. Embriological induction and predation ecology in Daphnia pulex. Limnol. Oceanogr., 26: 219-223.

Krylov, P.I., 1992. Density-dependent predation of Chaoborus flavicans on Daphnia longispina in a small lake: the effect of prey size. Hydrobiologia, 239: 131-140.

Lampert, W. 1994. Phenotypic plasticity in the size at first reproduction in Daphnia magna. Verh. int. Ver. Limnol., 25: 2362-2365.

Luecke, C. \& A.H. Litt. 1987. Effects of predation by Chaoborus flavicans on crustacean zooplankton of Lake Lenore, Washington. Freshwat. Biol., 18: 185-192.

Morabito, G. \& A. Oggioni. 2001. Evoluzione pluriennale della comunità fitoplanctonica in un lago piccolo e poco profondo (Lago di Candia, Nord Italia) analizzata con metodi agglomerativi (Cluster Analysis). Atti Associazione Italiana Oceanologia Limnologia, 14: 229-238.

Mort, M. 1986. Chaoborus predation and the function of phenotypic variation in Daphnia. Hydrobiologia, 133: 39-44

Mumm, H. 1997. Effects of competitors and Chaoborus predation on the cladocerans of a eutrophic lake: an enclosure study. Hydrobiologia, 360: 253-264.

Received: May 2001

Accepted: November 2001
Mumm, H. \& A.F. Sell. 1995. Estimating the impact of Chaoborus predation on zooplankton: a new design for in situ enclosures studies. Arch. Hydrobiol., 134: 195-206.

Neill, W.E. 1981. Impact of Chaoborus predation upon the structure and dynamics of a crustacean zooplankton community. Oecologia, 48: 164-177.

Neill, W.E. 1984. Regulation of rotifer densities by crustacean zooplankton in an oligotrophic montane lake in British Columbia. Oecologia, 61: 175-181.

Paloheimo, J.E. 1974. Calculations of instantaneous birth rate. Limnol. Oceanogr., 19: 692-694.

Pastorok, R.A. 1981. Prey vulnerability and size selection by Chaoborus larvae. Ecology, 62: 1311-1324.

Repka, S., M. Walls \& M. Ketola. 1995. Neck spine protects Daphnia pulex from predation by Chaoborus, but individuals with longer tail spine are at a greater risk. $J$. Plankton Res., 17: 393-403.

Riessen, H.P. 1992. Cost-benefit model for the induction of an antipredator defense. Am. Nat., 140: 349-362.

Riessen, H.P. 1994. Morphological response of Daphnia to Chaoborus predation. Verh. int. Ver. Limnol., 25: 23822386.

Riessen, H.P. 1999. Predator-induced life history shifts in Daphnia: a synthesis of studies using meta-analysis. Can. J. Fish. aquat. Sci., 56: 2487-2494.

Riessen, H.P. \& W.G. Sprules. 1990. Demographic costs of antipredator defenses in Daphnia pulex. Ecology, 71: 1536-1546.

Spitze, K. 1991. Chaoborus predation and life-history evolution in Daphnia pulex: temporal pattern of population diversity, fitness, and mean life history. Evolution, 45: 8292.

Stibor, H. 1992. Predator induced life-history shifts in a freshwater cladoceran. Oecologia, 92: 162-165.

Stibor H. \& J. Lüning. 1994. Predator-induced phenotypic variation in the pattern of growth and reproduction in Daphnia hyalina (Crustacea: Cladocera). Functional Ecology, 8: 97-101.

Swift, M.C. 1992. Prey capture by the fourth larval instars of Chaoborus cristallinus. Limnol. Oceanogr., 37: 14-24.

Taylor, B.E. \& W. Gabriel. 1992. To grow or not to grow: optimal resource allocation for Daphnia. Am. Nat., 139: 248266.

Vanni, M.J. 1988. Freshwater zooplankton community structure: introduction of large invertebrate predators and large herbivores to a small-species community. Can. J. Fish. aquat. Sci., 45: 1758-1770. 